\title{
Effect of Yb: Fiber Laser on Surface Roughness and Wettability of Titanium
}

\begin{abstract}
SUMMARY
Background/Aim: In recent years, the role of computer aided design (CAD) and computer aided manufacturing (CAM) in dentistry has increasingly become important. However, the influence of different $\mathrm{Yb}$ : fiber laser applications on surface roughness of CAD/CAM implant has rarely been studied. The aim of this study is to investigate the effect of different $Y b$ : fiber laser parameters on the surface roughness of CAD/CAM titanium. Material and Methods: Titanium samples, produced by CAD/CAM, were divided into 11 groups according to laser parameters such as scanning types (ST), application angles (AA) and hatch interval (HI). The surface roughness of CAD/CAM titanium was examined for each group. Wettability contact angles (CA) were also determined. Results: The highest surface roughness $\left(43 \mu \mathrm{m}\right.$ ) value was obtained for Group 10 (three-ways $S T, 60^{\circ} \mathrm{AA}$, $0.07 \mu \mathrm{m} \mathrm{HI})$. The lowest value $(2.77 \mu \mathrm{m})$ after control group was obtained for Group 6. Surface roughness values, for Group 3, Group 9 and Group 10 were significantly higher than for the other groups $(P=0.000)$. In contact angle evaluations, the highest contact angle $\left(144^{\circ}\right)$ was observed in Group 10, while the lowest $\left(95^{\circ}\right)$ was observed in control group. Conclusions: Surface roughness was dependent on mixed effect of the laser application parameters. Three-ways $S T, 60^{\circ} \mathrm{AA}, 0.07 \mu \mathrm{m} \mathrm{HI}$ provided highest surface roughness and wettability contact angles. The surface roughness values of one-way ST, $0.06 \mu \mathrm{m} \mathrm{HI,} \mathrm{two-ways} \mathrm{HT,} 45^{\circ} \mathrm{AA}$ and $0.08 \mu \mathrm{m} \mathrm{HI}$ and threeways $S T, 60^{\circ} \mathrm{AA}$ and $0.07 \mu \mathrm{m} \mathrm{HI}$ were significantly higher than for the other groups $(P=0.000)$.
\end{abstract}

Key Words: Titanium, CAD/CAM, Yb: Fiber Laser, Surface Roughness, Scanning Type, Hatch Interval

\author{
Berivan Dündar Yılmaz ${ }^{1}$, İbrahim Halil Tepe ${ }^{2}$, \\ Remzi Nigiz ${ }^{1}$, Zelal Seyfioğlu Polat ${ }^{1}$, Server \\ Mutluay Unal ${ }^{3}$ \\ ${ }^{1}$ Department of Prosthodontics, Faculty of \\ Dentistry, University of Dicle, Diyarbakir, \\ Turkey \\ ${ }^{2}$ Department of Prosthodontics, Faculty \\ of Dentistry, University of Afyonkocatepe, \\ Afyonkarahisar, Turkey
}

\section{ORIGINAL PAPER (OP)}

Balk J Dent Med, 2022;52-57

\section{Introduction}

The bond strength between titanium and resin or titanium and ceramic is very important for the prosthetic treatment. Such bond strength is provided by the surface roughness (SR) of titanium and ceramic and also by the resins used. Therefore, various studies have been carried out on surface treatments using different implants, ceramics and resins ${ }^{1-3}$. Different surface treatment methods such as acid etching, sandblasting and laser etching were used to create the appropriate surface roughness ${ }^{3-6}$. However, studies on dental titanium and surface treatment methods are still important for clinical trials.

In recent years, the role of $\mathrm{CAD} / \mathrm{CAM}$ in prosthetic implant dentistry, computer-aided abutments, CAD/CAM systems for crown and bridge restorations has increasingly become important ${ }^{7-14}$. High energy laser sources such as high-energy nanosecond fiber amplifier and high-average power picosecond $\mathrm{Yb}$-doped fiber amplifier, and also microsecond-pulsed $\mathrm{Yb}$ : fiber laser system and ultrashortpulsed laser, high energy laser with fiber based high repetition rate were introduced ${ }^{15-18}$. The effect of several 
application parameters was investigated ${ }^{19,20}$. The effects of ultrafast fiber laser application on the bond strength of resin cement to titanium have been studied ${ }^{21-24}$. However, the influence of different $\mathrm{Yb}$ : fiber laser applications on surface roughness of CAD/CAM implant has rarely been studied.

In a previous study, the effect of several parameters such as pulse duration, repetition rate, fluency of energy dose, and scanning velocity was determined in terms of ablation efficiency of high average power ultrafast laser for stainless steel, aluminum, copper and molybdenum and processing quality ${ }^{19}$. The effect of these parameters was found to be strongly material dependent. In another study, surface roughness for two CAD/CAM glass fiber posts was found to be dependent on milling angulations ${ }^{20}$. Ytterbium-doped fiber laser irradiation was also found to be effective for roughening the zirconia surface ${ }^{21}$. The highest surface roughness value was obtained at laser power of $20 \mathrm{~W}$ and frequency rate of $100 \mathrm{kHz}$. Best wettability characteristic was observed at $5 \mathrm{~W}$ and $60 \mathrm{KHz}$. The result of this study revealed a necessity to adjust power and frequency to achieve optimum results. Furthermore, the effect of laser beam parameters such as current, spot diameter and pulse duration were investigated for the mechanical and physical properties of cast commercially pure titanium ${ }^{22}$. The laser treatment was found to decrease the subsurface hardness and increase the hardness between $75 \mu \mathrm{m}$ and $400 \mu \mathrm{m}$ in depth when compared to the hardness of control specimens. On the other hand, effects of laser pulse amounts on surface roughness, and wettability of thin titanium sheet were studied for implant fabrication ${ }^{23}$. A scanning speed of $100 \mu \mathrm{m} / \mathrm{ms}$ was found desirable for the surface of treated titanium sheets. In a study on the effect of ultrafast fiber laser application on the bond strength between resin cement and titanium, the highest bond strength values were observed in the laser application group $^{24}$. In another study on effect of surface texture on the adhesion performance of laser treated Ti6Al4V Alloy, laser texturing provided up to eightfold and 30\% higher shear strength compared to plain ${ }^{25}$. A study on the influence of laser parameters and scanning strategies on the mechanical properties of a stochastic porous material underlines the necessity for optimizing structure parameters to maximize mechanical performance ${ }^{26}$. These studies provide a basis for the present study.

The aim of this study was to investigate the effect of different $\mathrm{Yb}$ : fiber laser parameters on the surface roughness of titanium produced by $\mathrm{CAD} / \mathrm{CAM}$. For this purpose, the effect of laser application parameters as scanning types (ST), application angles (AA) and hatch interval (HI) on surface roughness of $\mathrm{CAD} / \mathrm{CAM}$ titanium was examined. Wettability contact angles were also determined.

\section{Material and Methods}

\section{Producing Titanium Discs and Groups}

Titanium discs, with $6 \mathrm{~mm}$ diameter and $3 \mathrm{~mm}$ height, were used in this study and were prepared with CAD/CAM technology by using Kera Ti 5-Disc Cad-Cam Titanium (Grade 5 Ti6Al4V based alloy). After the design of the samples in the software program, the production of titanium discs was started with the milling machine. The Kera Ti 5-Disc titanium blocks placed in the CAD/ CAM unit were milled according to the design. After milling, a total of 231 cylindrical samples were separated from the attachment regions. These samples were divided into 11 groups ( $\mathrm{n}=7)$ according to the laser application.

\section{Selecting Laser Parameters and Groups}

Using standard laser LF20 apparatus, at a set-up of 20 $\mathrm{W}$ and the focal length of $180 \mathrm{~mm}$; Yb: fiber laser with $20 \mathrm{~W}$ of power was applied to titanium disc surfaces by changing its application parameters such as Scanning type (ST), Application angle (AA) and Hatch interval (HI). Distribution of application parameters to groups is shown in Table 1 .

Table 1. Laser applied groups (N: 231) in terms of Scanning Types (ST), Application Angles (AA) and Hatch Interval (HI)

\begin{tabular}{ccccc}
\hline Group & $\begin{array}{c}\text { Scanning type } \\
(\mathrm{ST})\end{array}$ & $\begin{array}{c}\text { Application } \\
\text { angle }(\mathrm{AA})\end{array}$ & $\begin{array}{c}\text { Hatch interval } \\
(\mathrm{HI})\end{array}$ & $\mathrm{n}$ \\
\hline 1 & One-way & 90 & 0.04 & 21 \\
2 & One-way & 90 & 0.05 & 21 \\
3 & One-way & 90 & 0.06 & 21 \\
4 & One-way & 90 & 0.07 & 21 \\
5 & One-way & 90 & 0.08 & 21 \\
6 & Two-ways & 90 & 0.07 & 21 \\
7 & Two-ways & 90 & 0.08 & 21 \\
8 & Two-ways & 45 & 0.07 & 21 \\
9 & Two-ways & 45 & 0.08 & 21 \\
10 & Three-ways & 60 & 0.07 & 21 \\
11 (control) & & - & & - \\
\hline
\end{tabular}

Laser was applied to the 21 titanium surfaces selected for each group using the same application parameters for each surface. Of the 21 samples; 7 were used for SEM, 7 for profilometer, and 7 for the wettability measurements.

\section{Scanning}

The height of the titanium disc was calculated so that the distance between the scan head of the laser device and the surface of the sample titanium discs is $180 \mathrm{~mm}$; it was manually arranged in the relevant section of the laser device. Three scanning types, such as one-way, two-ways and three-ways scanning, were applied to the samples to be screened (Figures 1a-c). 


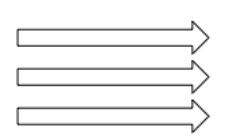

a

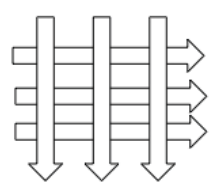

b

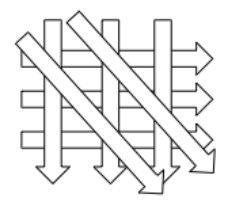

C
Figure 1. a) One-way scanning b) Two-ways scanning c) Three-ways scanning

The surface area of the titanium discs to be roughened was calculated and transferred to the computer program, as well as all other parameters.

No scanning was performed in the control group; one-way scanning was made in Group 3, and three-ways scanning was performed in Group 10.

\section{Surface roughness measurements for titanium disc samples}

Surface roughness measurement was performed with a profilometer device (Dektak 8 Advanced Development Profiler, Veeco, Plainview, NY, USA). Surface roughness value was determined by scanning the $1000 \mu \mathrm{m}$ X 4000 $\mu \mathrm{m}$ area with the diamond pointed needle covering the sample surface completely. The mean Sa value was determined from the measurements of the samples.

\section{Measurements of wettability contact angles of tita- nium disc samples}

The contact angle values of surface treated titanium discs were measured with Attension Theta (Biolinscientific, Sweden) branded goniometer (Optical Contact Angle/Surface Tension Measuring Device: TAYG) founded at R\&D Training and Measurement Center in Middle East Technical University. The contact angle was determined by direct observing the angle between the titanium surface and a drop of liquid left on the flat surface of the surface-treated titanium samples and control group. For this purpose, a comparative microscope compatible with the goniometer was used. The droplet was visualized and the $\theta$ was calculated directly and the following standard classification was used for the relationship between wettability and the $\theta$ :

- The contact angle is $0^{\circ}$ if the fluid is fully spread on the surface.

- If the contact angle is less than $90^{\circ}$, the surface is considered to be a hydrophilic.

- If the contact angle is greater than $90^{\circ}$, then the surface is considered to be a hydrophobic ${ }^{27}$.

\section{SEM Analysis}

The surface images of titanium discs roughened with fiber laser using different application parameters and the control group without roughening process were studied by SEM (Scanning Electron Microscope). The images were obtained at Afyon Kocatepe University Research Center.

\section{Statistical Analysis}

Results of surface roughness and contact angles were presented as the mean \pm standard deviation (SD). An analysis of variance (One-way Anova) and Tukey's HSD post hoc tests with $95 \%$ confidence were used for multiple comparisons of 11 groups and test results were considered statistically significant for $\mathrm{p}<0.05$.

\section{Results}

Figures 2 a-c show representative images obtained for the types of scans evaluated by the profilometer for surface roughness.

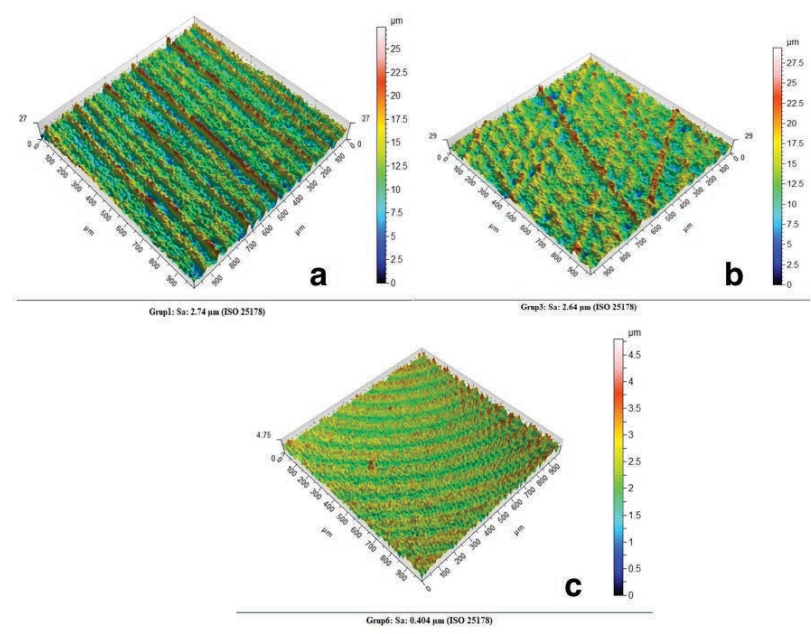

Figure 2. a) Profile of Group 3 b) Profile of Group 10 c) Profile of Group 11

Observing the surface roughness values of the groups, the mean values of all groups were higher than for the control group. Group 2 was not different from Group $6(\mathrm{P}=0.797)$ and Group 4 was not different from Group 7 $(\mathrm{P}=1.00)$. Other groups were highly significantly different from each other $(\mathrm{P}=0.000)$.

The control group showed the lowest surface roughness $(0.404 \mu \mathrm{m})$. The highest surface roughness was obtained for Group 10 (three-ways ST, 60 $0^{\circ} \mathrm{AA}$ and 0.07 $\mu \mathrm{m} \mathrm{HI})$. The lowest surface roughness after control group was obtained for Group 6 (two-ways ST, 90 AA and 0.07 $\mu \mathrm{m} \mathrm{HI}$ ). The surface roughness's of Group 3 (one-way ST, $0.06 \mu \mathrm{m} \mathrm{HI}$ ) and Group 9 (two-ways HT, 45 AA and $0.08 \mu \mathrm{m} \mathrm{HI})$ were nearly $28 \mu \mathrm{m}$ and $27 \mu \mathrm{m}$, respectively. Group 3, Group 9 and Group 10 were highly significantly different from other groups $(\mathrm{P}=0.000)$. 
The mean surface roughness and contact angles values of the groups are shown in Table 2 with standard deviations (SD). Although the hatch interval increased gradually from Group 1 to Group 6, surface roughness did not show a steady increase or decrease for oneway scanning. This implied that HI was not an efficient factor alone for surface roughness. This classification showed that the mixed effect of the three parameters affects surface roughness rather than a parameter alone. All wettability angles are greater than $90^{\circ}$. Therefore, all surfaces examined were hydrophobic.

Table 2. The mean surface roughness and contact angles of the groups

\begin{tabular}{|c|c|c|c|c|}
\hline \multicolumn{5}{|c|}{$\mathrm{X} \pm \mathrm{SD}$} \\
\hline Group & $\begin{array}{c}\text { Surface } \\
\text { Roughness }\end{array}$ & $\begin{array}{c}\text { Std. } \\
\text { Deviations }\end{array}$ & Contact Angles & $\begin{array}{c}\text { Std. } \\
\text { Deviations }\end{array}$ \\
\hline 1 & 5.304 & 0.152 & 117.286 & 0.951 \\
\hline 2 & 3.056 & 0.257 & 112.286 & 1.496 \\
\hline 3 & 27.800 & 0.362 & 104.286 & 0.951 \\
\hline 4 & 15.801 & 0.264 & 125.000 & 1.291 \\
\hline 5 & 4.087 & 0.077 & 113.571 & 0.787 \\
\hline 6 & 2.767 & 0.159 & 110.000 & 0.817 \\
\hline 7 & 15.906 & 0.446 & 125.143 & 1.069 \\
\hline 8 & 6.137 & 0.182 & 115.286 & 0.951 \\
\hline 9 & 26.603 & 0.601 & 130.000 & 1.291 \\
\hline 10 & 43.006 & 0.329 & 144.000 & 1.291 \\
\hline 11 & 0.404 & 0.102 & 95.000 & 1.291 \\
\hline
\end{tabular}

Although the angles were close to each other, the highest contact angle $\left(144^{\circ}\right)$ was observed in Group 10 (three-ways ST, $60^{\circ} \mathrm{AA}, 0.07 \mu \mathrm{m} \mathrm{HI}$ ), while the lowest contact angle $\left(95^{\circ}\right)$ was observed in Group 11 (control group). The wettability decreases as the contact angle increases. When both wettability and roughness were evaluated together, Group 3 was considered to be the most appropriate group. Being the most appropriate group is consistent with the statistical evaluation that revealed the differentiation of Group 3 from the other groups $(p<0.05)$.

Representative images showing the wettability contact angles of Group 3, Group 10 and the control group are shown in Figures 3 a-c respectively.

When SEM images were examined, pit and irregularity were not observed in the control group. However, both Group 3 and Group 10 offered a very different pattern from the control group. In the case of the Group 3, a large number of pits was observed, and a regular and intense roughness pattern was followed. Although a similar image was seen in Group 10, fewer pits and a relatively more irregular roughness pattern were observed compared to Group 3. SEM images are given in Figures 4 a-c.

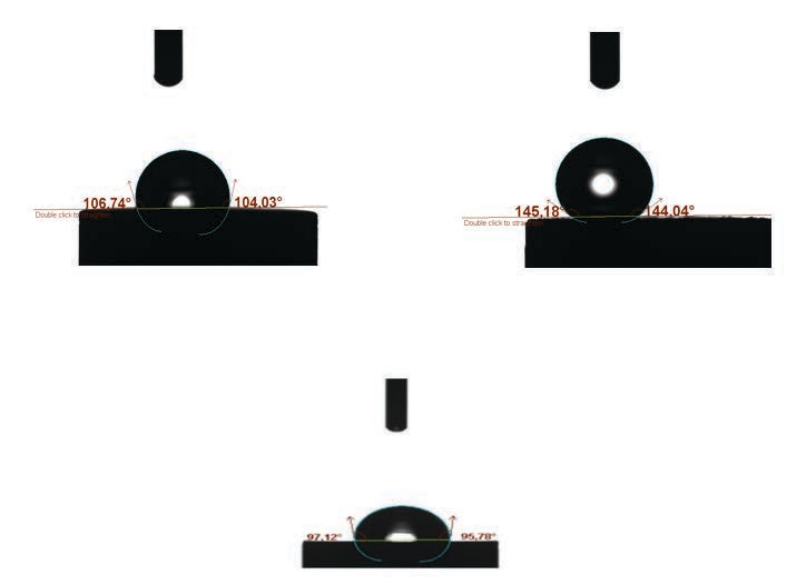

Figure 3. a) CA for Group 3 b) CA for Group 10 c) CA for Group 11 SEM Findings

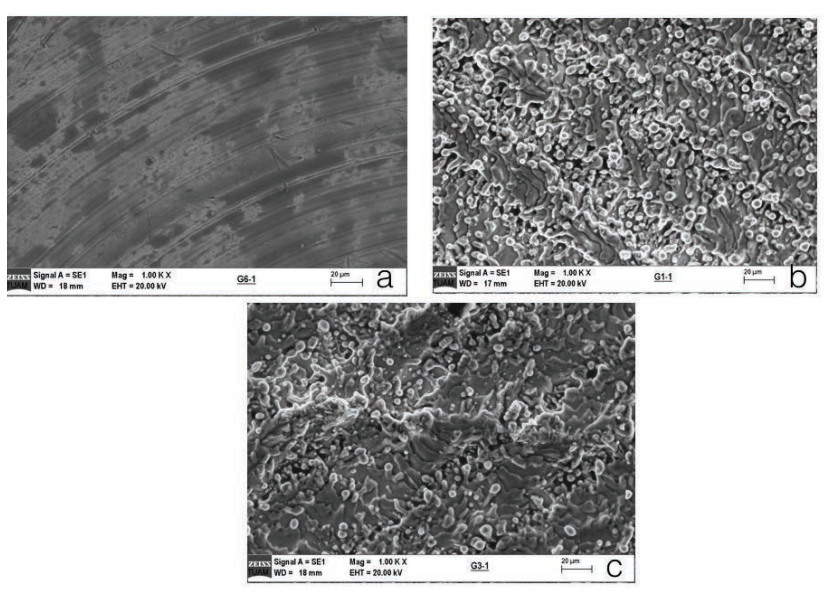

Figure 4. a) SEM image of Group 11 b) SEM image of Group 3 c) SEM image of Group 10.

\section{Discussion}

Literature given in the introduction reveals that several parameters such as fiber laser pulse duration, fiber laser pulse number, repetition rate, fluency of energy dose, and scanning velocity, milling angulations, and laser texturing influence surface roughness and wettability of materials. Selecting the optimum value for each parameter is essential to obtain the deepest surface roughness and the appropriate wettability contact angle. In present study scanning type, application angle and hatch interval were selected as variables, and other parameters were kept constant. High surface roughness $(43 \mu \mathrm{m})$ and wide wettability contact angle $\left(144^{\circ}\right)$ were obtained using three-way ST, $60^{\circ} \mathrm{AA}$ and $0.07 \mu \mathrm{m} \mathrm{HI}$. Present wettability contact angle showed that metallic surfaces are hydrophobic. This result is consistent with a previous result noted as about $151.5^{\circ}{ }^{28}$. Our highest 
surface roughness value $(43.15 \mu \mathrm{m})$ is three times higher than $15.06 \mu \mathrm{m}$, which is determined by the change in laser scanning speed and change of surface morphology in the Zhang et al. study ${ }^{28}$.

In the present study, we tried to obtain optimum HI values using variable interval ranges for one-way scanning. However, our findings indicated that $\mathrm{HI}$ alone is not an effective factor for surface roughness. Therefore, it became unnecessary to use changing $\mathrm{HI}$ values for other scanning types. However, in this study, the effect of HI values on surface roughness was not only checked for one-way scanning, but also for other types of screening using similar HI ranges. Our findings are consistent with a recent study suggesting that the hatch rotation angle has little effect on top surface roughness and strength of the parts $^{29}$.

It is well known that the physical adhesion between the titanium surface and the ceramic is the bonding strength that has been subjected to numerous studies. The bond strength is directly related to surface roughness and wettability. It is also well known in the literature that high wettability and surface roughness provide a strong bonding strength between titanium alloy and ceramic or resin material ${ }^{30,31}$. For these reasons, the selected parameters of Group 3 produce the best conditions in terms of both Contact Angle and Surface Roughness. In addition, there are some alternative methods used for material structuration. The results of this study are also in accordance with similar studies investigating the effect of several parameters on titanium surface.

In this study, surface roughness and wettability were evaluated after $\mathrm{Yb}$ : fiber laser irradiation with different hatch intervals and scanning type. It is thought that the bond strength will increase by applying the most suitable parameters found in this study. As a limitation of this study, the bond strength was not investigated and needs to be analyzed in subsequent studies.

\section{Conclusions}

When application of different fiber laser parameters were evaluated; the highest surface roughness (Sa: 43.0 $\mu \mathrm{m}$ ) was observed in Group 10 (Three-ways ST, 60 AA, $0.07 \mu \mathrm{m} \mathrm{HI).} \mathrm{The} \mathrm{results} \mathrm{of} \mathrm{SEM} \mathrm{analysis} \mathrm{showed}$ irregular pits in Group 10, and regular pits were observed in Group 3. SEM analysis supported highest surface roughness values found for Group 1 and 3. In contact angle evaluations, the highest contact angle $\left(144^{\circ}\right)$ was observed in Group 10, which is in accordance with SEM findings which reveled. irregular pits and intense roughness . On the other hand, the lowest contact angle $\left(104^{\circ}\right)$ after control group was observed in Group 3, which can be explained by regular pits and low roughness observed with SEM
Acknowledgments: We thank Professor Ali YILMAZ for his contribution to statistical analysis.

\section{References}

1. Cai Z, Bunce N, Nunn ME, Okabe T. Porcelain adherence to dental cast CP titanium: effects of surface modifications. Biomaterials, 2001;22:979-986.

2. Veljee TM, Shruthi CS, Poojya R. Evaluation and comparison of the effect of different surface treatment modifications on the shear bond strength of a resin cement to titanium: An in vitro study. J Indian Prosthodont Soc, 2015;15:308-312.

3. Egoshi T, Taira Y, Soeno K, Sawase T. Effects of sandblasting, $\mathrm{H} 2 \mathrm{SO} 4 / \mathrm{HCl}$ etching, and phosphate primer application on bond strength of veneering resin composite to commercially pure titanium grade 4. Dent Mater J, 2013; 32:219-227.

4. Kim JT, Cho SA. The effects of laser etching on shear bond strength at the titanium ceramic interface. J Prosthet Dent, 2009;101:101-106.

5. Göze Saygın A, Ozdemir AK, Görler O. Influence of various laser surface modifications on SBS of titanium and zirconium oxide substructure. CSJ, 2017;38:245-255.

6. Hao L, Lawrence J. Effects of Nd:YAG laser treatment on the wettability characteristics of a zirconia-based bioceramic. Opt Laser, 2006;44:803-814.

7. Kapos T, Ashy LM, Gallucci GO, Weber HP, Wismeijer D. Computer-aided design and computer-assisted manufacturing in prosthetic implant dentistry. Int $\mathrm{J}$ Oral Maxillofac Implants, 2009;24:110-117.

8. Priest G. Virtual-designed and computer-milled implant abutments. J Oral Maxillofac Surg, 2005;63:22-32.

9. Miyazaki T, Hotta Y. CAD/CAM systems available for the fabrication of crown and bridge restorations. Aust Dent J, 2011;56:97-106.

10. Abduo J, Lyons K. Rationale for the use of CAD/ CAM technology in implant prosthodontics. Int $\mathrm{J}$ Dent, 2013;2013:768121.

11. Parpaiola A, Norton MR, Cecchinato D, Bressan E, Toia M. Virtual abutment design: a concept for delivery of $\mathrm{CAD} /$ CAM customized abutments- report of a retrospective cohort. Int J Periodontics Restorative Dent, 2013;33:51-58.

12. Beuer F, Schweiger J, Edelhoff D. Digital dentistry: an overview of recent developments for CAD/CAM generated restorations. Br Dent J, 2008;204:505-511.

13. Ender A, Mörmann WH, Mehl A. Efficiency of a mathematical model in generating $\mathrm{CAD} / \mathrm{CAM}$ partial crowns with natural tooth morphology. Clin Oral Investig, 2011;15:283-289.

14. Sorensen JA. CAD/CAM: Converging technologies, improved milling materials expand dental applications. Compend Contin Educ Dent, 2012;33:538-539.

15. Limpert J, Hofer S, Liem A, Zellmer H, Tünnermann A, Knoke S, et al. 100-W average-power, high-energy nanosecond fiber amplifier. Appl Phys B, 2002;27:477-479.

16. Engelbrecht M, Wandt D, Kracht D. Microsecond-pulsed ytterbium fiber laser system with a broad tuning range and a small spectral line width. Proc SPIE, 2001;6453:21-28. 
17. Ackerl N, Warhanek M, Gysel J, Wegener K. Ultrashortpulsed laser machining of dental ceramic implants. J Eur Ceram Soc, 2018;39:1635-1641.

18. Nickel D, Liem A, Limpert J, Zellmer H, Griebner U, Unger $\mathrm{S}$, et al. Fiber based high repetition rate, high energy laser source applying chirped pulse amplification. Opt Commun, 2001;190:309-315.

19. Lopez J, Mincuzzi G, Devillard R, Zaouter Y, Hönninger C, Mottay E, et al. Ablation efficiency of high average power ultrafast laser. J Laser Appl, 2015;27:S28008.

20. Ruschel GH, Gomes ÉA, Silva-Sousa YT, Pinelli RGP, Sousa-Neto MD, Pereira GKR, et al. Mechanical properties and superficial characterization of a milled CAD-CAM glass fiber post. J Mech Behav Biomed Mater, 2018;82:187192.

21. Mutluay S, Özkır S, Polat Z, Guven S, Asutay H. The effect of ytterbium-doped fiber laser with different parameters on physical properties of zirconia surface. Photomed Laser Surge, 2016;35:157-163.

22. Hayashi T, Watanabe I, Kurogi T, Shiraishi T, Murata H. Effect of laser emission parameters on mechanical and physical properties of cast pure titanium. J Spectrosc, $2014 ; 862305$.

23. Radmanesh M, Kiani A. Effects of laser pulse numbers on surface biocompatibility of titanium for implant fabrication. J Biomater Nanobiotechnol, 2015;6:168-175.

24. Ates SM, Korkmaz FM, Bagis EA. The effect of ultrafast fiber laser application on the bond strength of resin cement to titanium. Lasers Med Sci, 2017;32:1121-1129.

25. Pietro MA, Luca BA, Demir AG, Previtali B. Effect of surface texture on the adhesion performance of laser treated Ti6Al4V alloy. J Adhes, 2015;91:518-537.

26. Ghouse S, Babu S, Van Arkel RJ, Nai K, Hooper PA, Jeffers JRT. The influence of laser parameters and scanning strategies on the mechanical properties of a stochastic porous material. Mater Des, 2017;131:498-508.
27. Zissis A, Yannikakis S, Jagger RG, Waters MGJ. Wettability of denture materials. Quintessence Int, 2001;32:457-462.

28. Zhang H, Gu D, Ma C, Xia M, Guo M. Surface wettability and superhydrophobic characteristics of Ni-based nanocomposites fabricated by selective laser melting. Appl Surf Sci, 2019:476;151-160.

29. Robinson JH, Ashton IRT, Jones E, Fox P, Sutcliffe C. The effect of hatch angle rotation on parts manufactured using selective laser melting. Rapid Prototyp J, 2019;25:289-298.

30. Surmenova M, Nikityuk $P$, Hans $M$, Surmenev R. Deposition of Ultrathin Nano-Hydroxyapatite Films on Laser Micro-Textured Titanium Surfaces to Prepare a Multiscale Surface Topography for Improved Surface Wettability/Energy. Materials, 2016;9:862-877.

31. Hong MH, Min BK, Kwon TY. Fabricating High-Quality 3D-Printed Alloys for Dental Applications. Appl Sci, 2017;7:710-716.

Conflict of Interests: Nothing to declare.

Financial Disclosure Statement: Nothing to declare.

Human Rights Statement: None required.

Animal Rights Statement: None required.

Received on February 19, 2021.

Revised on April 12, 2021.

Accepted on September 24, 2021.

Correspondence

Berivan Dündar Yilmaz

Department of Prosthodontics

Faculty of Dentistry, University of Dicle

Diyarbakir, Turkey

e-mail: berivandndr@yahoo.com 